\title{
Influence of the SHI Irradiation on the XRD, AFM, and Electrical Properties of CdSe Thin Films
}

\author{
Rajesh Singh, Radha Srinivasan
}

Department of Physics, University of Mumbai, Santacruz (East), 400098 Mumbai, India

(Received 20 October 2016; published online 21 June 2016)

\begin{abstract}
Cadmium Selinide (CdSe) thin films prepared by thermal evaporation on glass substrates were irradiated with swift $(100 \mathrm{MeV}) \mathrm{Ni}^{+7}$ ions at fluences of $1 \times 10^{11}$ and $1 \times 10^{12} \mathrm{~cm}^{-2}$. The structural changes with respect to increasing fluence were observed by the means of X-ray diffraction (XRD). The modification in surface morphology and electrical properties has been analyzed as a function of fluence using XRD, AFM and I-V techniques. The AFM micrographs of irradiated thin films show the formation of small spherical grains and decrease in surface roughness with increasing fluence as well as I-V measurement revels that decrease in resistivity with increasing fluence.
\end{abstract}

Keywords: CdSe thin films, SHI, XRD, AFM, I-V.

DOI: $10.21272 /$ jnep.8(2).02036

PACS numbers: 68.37.Ps, 73.50. - h

\section{INTRODUCTION}

The Fabrication of chalcogenide semiconductors, IIVI compound semiconductor in varying sizes and shapes have drawn interest in the area of materials research because they find applications in non-linear optics and opto-electronics devices [1-4]. CdSe is an important material for the development of various application such as lasers [5], sensors [6], transistors [7], photoelectrodes [8], light emitting diode [9] and solar cells [10-15]. Currently the swift heavy ion (SHI) irradiation of materials has generated significant interest in the light of application of materials in high radiation zones [16]. SHI irradiation has been reported of CdSe/FTO thin films deposited by electro deposition method. After irradiating the films there is growth in the grain size and decrease in resistivity of the sample was observed from surface analysis and electrical properties [17]. In the present work, we investigate the surface morphology and electrical properties of the SHI irradiated (100 $\mathrm{MeV} \mathrm{Ni}^{+7}$ ion) by thermally evaporated CdSe thin film using XRD, AFM and I-V techniques.

\section{EXPERIMENTAL DETAILS}

CdSe thin films of thickness $200 \mathrm{~nm}$ were deposited on clean glass substrate at a pressure of $1 \times 10^{-6} \mathrm{mbar}$ on. Swift Heavy ion (SHI) irradiation of the as deposited CdSe films was done using 15 UD pelletron accelerator at Inter University Accelerator Center (IUAC), New Delhi, with $100 \mathrm{MeV} \mathrm{Ni}{ }^{+7}$ at fluences levels $1.0 \times 10^{11}$ and $1.0 \times 10^{12} \mathrm{~cm}^{-2}$. The focused ion beam was scanned over an area of $1 \mathrm{~cm}^{2}$ using a magnetic scanner to achieve the fluence uniformity across the sample surface. Simulation using SRIM code suggest that electronic and nuclear energy loss value for the CdSe are $1.88 \times 10^{1} \mathrm{eV} / \AA$ and $3.17 \times 10^{-2} \mathrm{eV} / \AA$ respectively. The nuclear energy loss in CdSe is negligible compare to electronic energy loss, therefore modifications in multilayer are expected to occure mainly due to electronic energy loss. The structural analysis of films was studied by X-ray diffractometer (Model JEOL 8030, $\lambda=0.1541 \mathrm{~nm}$ ). $\quad$ AFM measurements on the pre and post-irradiated thin films were performed with diInnova from Veeco Instruments. The quantitative analyses were carried out using Veeco software. All the AFM measurements have been performed in tapping mode (for both trace and retrace information) using a silicon nitride tip at ambient temperature. The current-voltage (I-V) characteristics of as deposited and irradiated films were investigated by using a Keithley Digital Multi Meter and a DC power supply.

\section{RESULTS AND DISCUSSIONS}

\subsection{X-ray Diffraction Studies}

The XRD patterns of CdSe films on glass substrates deposited at room temperature and irradiated at different fluences are show Fig. 1(a-c). The diffraction peaks observed close to $2 \theta=23^{\circ}, 25^{\circ}, 41^{\circ}, 45^{\circ}$ and $49^{\circ}$ are attributed to the (100), (002), (110), (103) and (201) planes, respectively of hexagonal
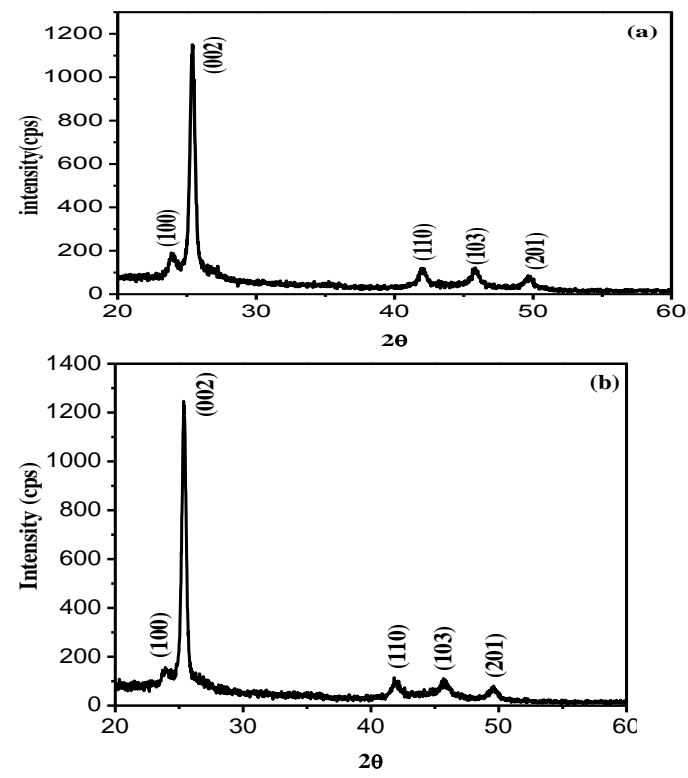


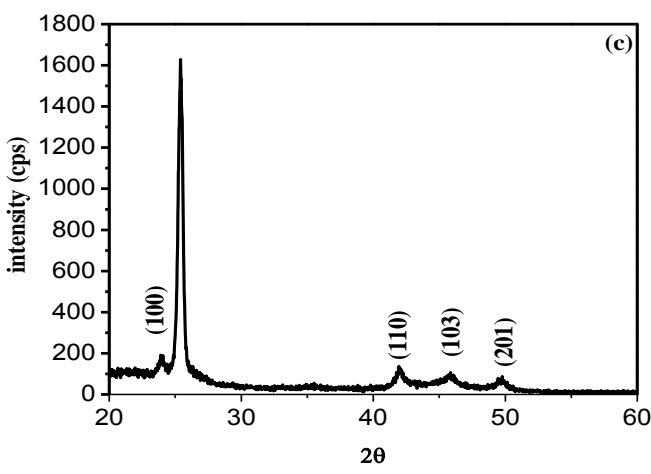

Fig. 1 - X-Ray Diffractogram (a) Pristine, (b) $1.0 \times 10^{11} \mathrm{~cm}^{-2}$, (c) $1.0 \times 10^{12} \mathrm{~cm}^{-2}$

Table 1 - Structural parameter of Cdse thin films

\begin{tabular}{|c|l|l|l|l|}
\hline Sample & $2 \theta(\mathrm{deg})$ & $d_{\text {obs }}(\AA)$ & $d_{\text {std }}(\AA)$ & $h k l$ \\
\hline \multirow{3}{*}{$\begin{array}{l}\text { as- } \\
\text { deposited }\end{array}$} & 23.93 & 3.716 & 3.720 & 100 \\
\cline { 2 - 5 } & 25.39 & 3.506 & 3.510 & 002 \\
\cline { 2 - 5 } & 41.59 & 2.151 & 2.151 & 110 \\
\cline { 2 - 5 } & 45.39 & 1.997 & 1.980 & 103 \\
\cline { 2 - 5 } & 49.65 & 1.835 & 1.834 & 112 \\
\hline $1 \times 10^{11}$ & 23.73 & 3.749 & 3.720 & 100 \\
\cline { 2 - 5 } & 25.34 & 3.513 & 3.510 & 002 \\
\cline { 2 - 5 } & 41.39 & 2.180 & 2.151 & 110 \\
\cline { 2 - 5 } & 45.29 & 2.001 & 1.980 & 103 \\
\cline { 2 - 5 } & 49.45 & 1.842 & 1.834 & 112 \\
\hline $1 \times 10^{12}$ & 23.43 & 3.795 & 3.720 & 100 \\
\cline { 2 - 5 } & 25.19 & 3.533 & 3.510 & 002 \\
\cline { 2 - 5 } & 41.19 & 2.190 & 2.151 & 110 \\
\cline { 2 - 5 } & 45.09 & 2.009 & 1.980 & 103 \\
\cline { 2 - 5 } & 49.25 & 1.849 & 1.834 & 112 \\
\hline
\end{tabular}

phase [18]. It was observed that after irradiation the intensity of the peak increases with increasing fluence, which indicate improvement in crystallinity and increase in grain size of the materials [19].

\subsection{Atomic Force Microscopy (AFM) Studies}

Fig. 3(a-c) shows the two dimensional AFM micrograph of as deposited and irradiated thin films. The scanning is done over an area of $5 \mu \mathrm{m} \times 5 \mu \mathrm{m}$. The AFM images of as deposited film shows the high roughness with spherical shape particles. On further increase in fluence, the vertical surface roughness is decreases than the initial roughness value. The CdSe films irradiated at $1 \times 10^{12} \mathrm{~cm}^{-2}$ show the most uniform surface with minimum surface average roughness value which can be suitable for developing photoelectrochemical solar cells. The variation of average roughness $\left(R_{a}\right)$ and RMS roughness $\left(R_{q}\right)$ is shown in Table 1 . The $R_{a}$ of the as-deposited film was measured to be about $0.35 \mathrm{~nm}$. The $R_{a}$ values calculated are 0.27 and $0.24 \mathrm{~nm}$ for the CdSe films deposited at fluence $1.0 \times 10^{11}$ and $1.0 \times 10^{12} \mathrm{~cm}^{-2}$ respectively, which attributes the smoothening of the surface. Decrease in roughness may arise due to the overlap of damaged zones which would lead to smoothening in heavily damaged surfaces.
Table 2 - Variation of Average roughness, rms roughness, and Average height obtained from AFM with fluence

\begin{tabular}{|l|l|l|l|}
\hline Fluence & $\begin{array}{l}\text { Average } \\
\text { surface } \\
\text { roughness } \\
R_{a}(\mathrm{~nm})\end{array}$ & $\begin{array}{l}\text { Rms surface } \\
\text { roughness } \\
R_{q}(\mathrm{~nm})\end{array}$ & $\begin{array}{l}\text { Average } \\
\text { height } \\
(\mathrm{nm})\end{array}$ \\
\hline Pristine & 0.35 & 1.3834 & 4.2950 \\
\hline $1.0 \times 10^{11}$ & 0.27 & 1.2114 & 3.8985 \\
\hline $1.0 \times 10^{12}$ & 0.24 & 0.9802 & 3.1902 \\
\hline
\end{tabular}
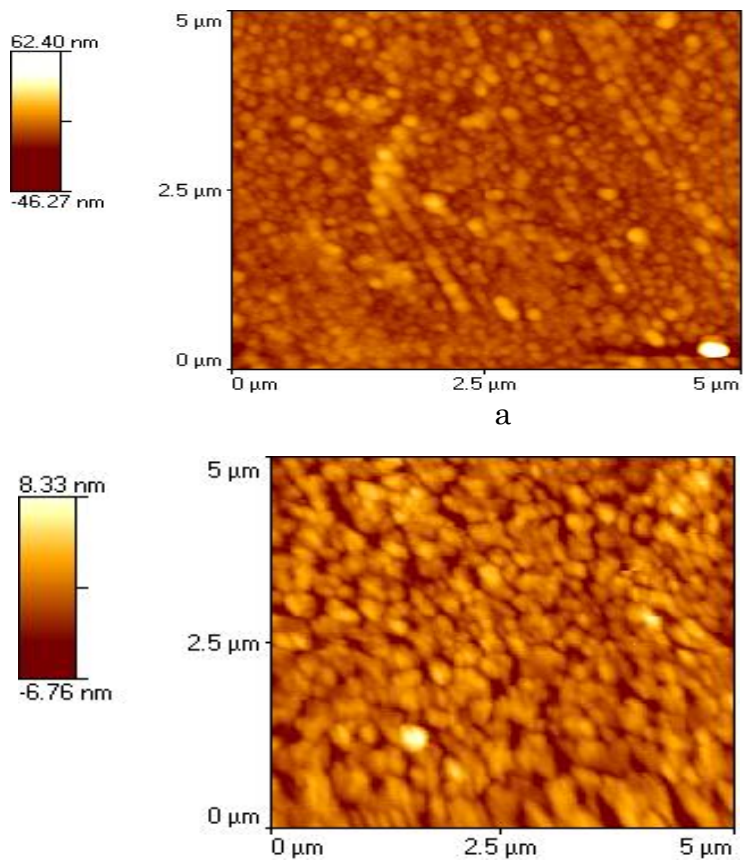

$\mathrm{b}$
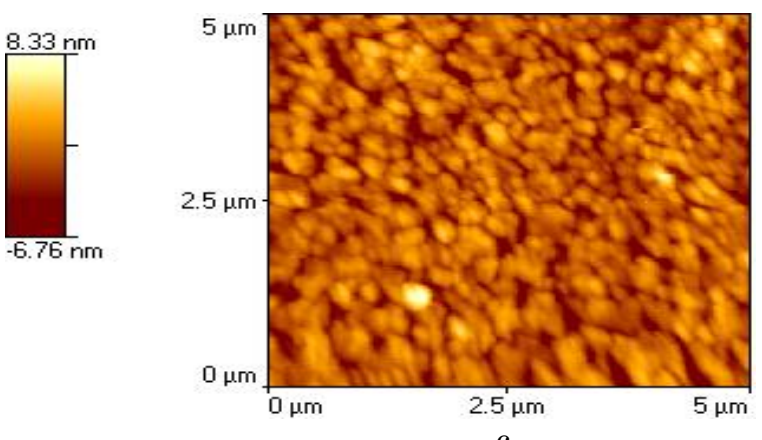

Fig. 2 - AFM micrographs of Pristine and irradiated films (a) Pristine, (b) $1.0 \times 10^{11} \mathrm{~cm}^{-2}$, (c) $1.0 \times 10^{12} \mathrm{~cm}^{-2}$

\subsection{Electrical Properties}

CdSe films as-deposited and irradiated was deposited onto Al/CdSe/ITO substrate for I-V measurement as Fig. 3 plot for as-deposited and irradiated $\left(1.0 \times 10^{11} \mathrm{~cm}^{-2}\right.$ and $\left.1.0 \times 10^{12} \mathrm{~cm}^{-2}\right)$ respectively. The electrical resistivity $(\rho)$ of the asdeposited and irradiated thin films was calculated using the relation concerned [20].

$$
\rho=2 \pi s \frac{V}{I}
$$

Here, $s$ is the distance between inner pair of probes 
The electrical resistivity is observed to be decreased with increase in irradiation fluences owing to increases in grain size and crystallinity.

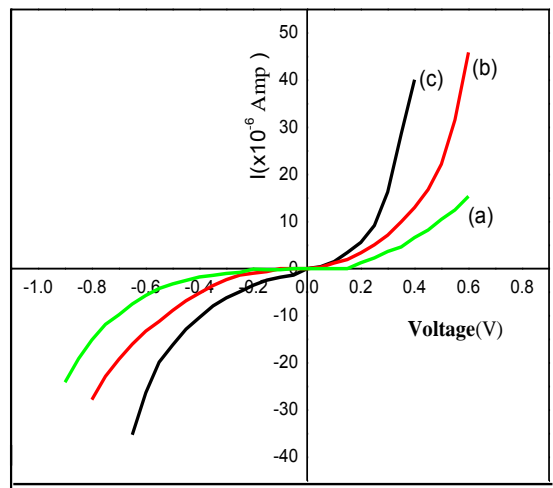

Fig. 3 - The current-voltage characteristics Pristine, (b) $1.0 \times 10^{11} \mathrm{~cm}^{-2}$, (c) $1.0 \times 10^{12} \mathrm{~cm}^{-2}$

(a)

\section{REFERENCES}

1. L.E. Brus, Appl. Phys. A 53, 465 (1991).

2. R.B. Kale, S.D. Sartlae, B.K. Chougule, C.D. Lokhande, Semicond. Sci. Technol. 19, 980 (2004).

3. E.U. Masumdar, V.B. Gaikwad, V.B. Pujari, V.B. Patil, L.P. Deshmukh, Mat. Chem. Phys.77, 669 (2003).

4. A.A. Yadav, M.A. Barote, E.U. Masumdar, Mat. Chem. Phys. 121, 53 (2010).

5. H.E. Esparza-Ponce, J. Hernandez-Borja, A. Reyes-Rojas, M. Cerventes-Sanchez, Y.V. Vorbier, R. Ramirez-Bon, J.F. PerezRobles, J. Gonzalez-Hernandez, Mater. Chem. Phys. 113, 824 (2009).

6. K. Subba Ramaiah, Y.K. Su, S.J. Chang, F.S. Juang, K. Ohdaira, Y. Shiraki, H.P. Liu, I.J. Chen, A.K. Bhatnagar, J. Cryst. Growth 224, 74 (2001).

7. D. Wang, H.P. Jakobson, R. Kou, J. Tang, R.Z. Fineman, D. Yu, Y. Lu, Chem. Mater. 18, 4231 (2006).

8. J.W. Edmund, E.M. Dale, R.N. Donald, B.E. Arthur, F.G. John, T.F. Kucch, J. Cryst. Growth 148, 63 (1995).

9. P.P. Hankare, V.M. Bhuse, K.M. Garadkar, S.D. Delekar, P.R. Bhagat, Semicond. Sci. Tech. 19, 277 (2004).

10. R. Mariappan, V. Ponnuswamy, M. Ragavendar, Optik 123, 1196 (2012).

\section{CONCLUSION}

It was observed from XRD that CdSe thin film asdeposited and irradiated at different fluences $\left(1.0 \times 10^{11} \mathrm{~cm}^{-2}\right.$ and $\left.1.0 \times 10^{12} \mathrm{~cm}^{-2}\right)$ shows that average grain size increases with increase in fluence. Changes in Surface morphology of the films were also noticed in the irradiated thin films. The morphology of the irradiated films reveals decrease in surface roughness, which is more desirable for developing photoelectrochemical solar cells. Also I-V measurement show decrease in the electrical resistivity with increase in fluence is due to increase in grain size.

\section{ACKNOWLEDGMENTS}

Authors thanks to Dr. Kanjilal, Dr. Fouran Singh and members of The Pelletron group, Inter University Accelerator Centre (IUAC), New Delhi, for carry out the irradiation work.

11. R. Kniproth, J.P. Rabe, J.T. McLesky Jr., D.Y. Wang, S. Kirstein, Thin Solid Films 518, 295 (2009).

12. I. Gur, N.A. Fromer, A.P. Alivisatos, J. Phys. Chem. B 110, 25543 (2006).

13. A. Van Calster, A. Vervaet, I. De Rycke, J. De Baets, J. Vanfleteren, J. Cryst. Growth 86, 924 (1989).

14. T. Gruszecki, B. Holmstrom, Sol. Energ. Mater. Sol. C. 31, 227 (1993).

15. L.P. Deshmukh, C.B. Rotti, K.M. Garadkar, Mater. Chem. Phys. 50, 45 (1997).

16. G. Khrypunova, A. Romeo, F. Kurdesauc, D.L. Batzner, H. Zogg, A.N. Tiwari, Sol. Energ. Mater. Sol. C. 90, 664 (2006).

17. Y.G. Gudage, F. Singh, R. Sharma, J. Sci. Rev. 2 No 2, 101 (2010).

18. JCPDS Card No. 77-2307

19. R. Singh, A.D. Yadav, V. Jadhav, S.K. Dubey, J. NanoElectron. Phys. 7 No 3, 03002 (2015).

20. A.U. Ubale, R.J. Dhokne, P.S. Chikhlikar, V.S. Sangawar, D.K. Kulkarni, Bull. Mater. Sci. 29 No 2, 165 (2006). 